\title{
A Mini Review of Patients' Access to Health Information in China
}

Mingwei Liu and Yinhuan $\mathrm{Hu}^{*}$

School of Medicine and Health Management, Tongji Medical College, Huazhong University of Science and Technology, Wuhan, Hubei, China

*Corresponding author: Yinhuan Hu, Associate Professor, School of Medicine and Health Management, Tongji Medical College, Huazhong University of Science and Technology, Wuhan, China, Tel: +86 13554285879; E-mail: hyh288@hotmail.com

Received date: May 19, 2016; Accepted date: June 27, 2016; Published date: June 30, 2016

Copyright: (c) 2016 Liu M, et al. This is an open-access article distributed under the terms of the Creative Commons Attribution License, which permits unrestricted use, distribution, and reproduction in any medium, provided the original author and source are credited.

\begin{abstract}
The purpose of this review is to briefly examine published articles regarding patients' access to health information in China. The searching was performed on the PubMed using MeSH words such as "consumer health information, health literacy, health education and drug information service". After preliminary screen, the contents were categorized as present situation, obstacles and future perspectives. In conclusion, patients now rely more on alternative access to health information to complement doctor consultation. Traditional alternative sources suffer low timeliness, credibility and efficiency. Though the current boom of online health information is promising, low quality of information, unequal access and poor design features have become obstacles for further development. In the future, Chinese authority and professional institutions will support the construction of search websites able to provide authentic health information. Training programs of health literacy will be employed universally, and pharmacist counselling will be well received.
\end{abstract}

Keywords: Health information; Access; Health literacy; China; Internet

\section{Introduction}

Chinese patients have long been suffering from a lack of authentic health information [1]. Recently, a national outrage over inaccurate, misleading and dangerous online health information [2] was triggered again by the death of Wei Zexi. Wei was a university student in his twenties.

After diagnosed with synovial sarcom, a rare kind of cancer, he was convinced to adopt an experimental cancer treatment by a paid advertisement, shown at the top of the online research results about this disease. It later turned out that the treatment had been questioned by Stanford due to its ineffectiveness and infeasibility, and was therefore abandoned in the U.S. As a result of the deceptive information, Wei's family had hoped in vain in spite of the considerable sum they had spent on the treatment.

However, it wasn't the first time that the inaccurate, incomplete or even deceptive health information had hurt people. Worse still this widespread phenomenon isn't limited online, nor would it stop yet. In what follows, a brief review will be given about patients' access to health information in China, in the hope of outlining the current situation, identifying the obstacles to reform and predicting future developments.

\section{Methods}

The searching was performed on the PubMed using MeSH words such as "consumer health information, health literacy, health education and drug information service". Keywords such as "China", "access", and "internet" were used to screen relevant articles.

Reference listed in these articles was also examined for further relevant materials. The search strategy and the number of results are shown in Table 1.

\begin{tabular}{|c|c|c|}
\hline Methods and Strategy & $\begin{array}{l}\text { Number of } \\
\text { results initially } \\
\text { retrieved }\end{array}$ & $\begin{array}{l}\text { Number fit the } \\
\text { results fit } \\
\text { selection } \\
\text { criteria }\end{array}$ \\
\hline \multicolumn{3}{|l|}{ PubMed $^{*}$} \\
\hline $\begin{array}{l}\text { (Consumer Health Information [MeSH } \\
\text { Terms]) and China }\end{array}$ & 38 & 10 \\
\hline $\begin{array}{l}((\text { Health Education [MeSH Terms] }) \text { and } \\
\text { China) and review [Publication Type] }\end{array}$ & 28 & 1 \\
\hline $\begin{array}{l}\text { (Health Literacy [MeSH Terms]) and } \\
\text { methods }\end{array}$ & 20 & 2 \\
\hline $\begin{array}{l}\text { (Drug Information Services [MeSH } \\
\text { Terms]) and China }\end{array}$ & 48 & 3 \\
\hline Conference reports in Chinese websites & & 3 \\
\hline $\begin{array}{l}\text { Reference listed in above articles or } \\
\text { others }\end{array}$ & & 14 \\
\hline Total & 134 & 33 \\
\hline \multicolumn{3}{|c|}{$\begin{array}{l}\text { "Step 1: Search MeSH Terms in MeSH Database. Step 2: The results in Step } 1 \\
\text { and keywords. The search strategy shown above is a simplified form of search } \\
\text { details }\end{array}$} \\
\hline
\end{tabular}

Table 1: The strategy and the number of results for review of patients' access to health information in China.

Any articles or conference reports that contain either qualitative information or quantitative data on current situation, obstacles or future perspectives of access to health information in China were selected as potential source of reference. Also included were comparative studies of similar problems identified in other countries. 
Page 2 of 4

\section{Current situation and obstacles}

According to the literature $[3,4]$, there are generally five kinds of health information sources: Doctors or healthcare providers, the traditional mass media, the internet, books or pamphlets and other sources like relatives and friends.

\section{Doctors or healthcare providers}

In the most traditional way, patients would refer to doctors for health information. A Singaporean research [5] revealed that about one quarter of Singaporean patients preferred doctors as their source of health information because of its accessibility and credibility. Likewise, a study in Hong Kong suggested $25.1 \%$ of the population preferring doctors [3]. Doctors are supposed to provide most information regarding health promotion and disease prevention. However, doctors in Chinese mainland are overloaded with patients, especially in secondary and tertiary hospitals, which prevent them from fulfilling the role of health information provider. This situation is caused by an unequal distribution of medical resources and underdeveloped referral system that induce patients to attend health care facilities of higher levels $[1,6]$. Data from the Whitepaper of Chinese doctors' practice showed that over 83 percent of doctors worked overtime, and that in 2014, 32.69\% worked over 60 hours a week [7]. As a result, doctors are only able to offer insufficient information limited to disease and treatment during short inquiries, thus largely impeded patients' access to authentic health information.

Additionally, the public trust in health sectors and in doctors particularly is in crisis [1], which further influences the credibility of health information obtained from doctors. The trust crisis is mainly caused by some unreasonable practice in hospitals and exaggerated media reports. For instance, revenue from pharmaceutical companies for prescribing constitutes, reportedly, more than half of Chinese hospitals' revenue [8]. Such economic incentives may result in overprescribing [9]. In fact, China has been reported to prescribe twice as many antimicrobials as recommended by the WHO, and three times as many injections as prescribed in comparable countries [10]. In addition, media coverage of some patients' complaints have pointed to relatively high expenditures on hospital care, poor quality of services, and use of low-quality medicines [1]. All of these factors have played their parts in causing the trust crisis. Under such circumstances, Chinese patients would like to seek alternative access to health information for complementing.

\section{Alternatives}

Traditional mass media such as radio, newspaper and television, remains the most favoured alternative access to health information in China. Suggested by a 2010 research in Hong Kong, 49.2 people use traditional mass media as their main source of health information [3]. However, it has been widely criticized that Chinese mass media, which should have been a popular site of medical education, have instead focused excessively on medical disputes [11]. Furthermore, commercial factors also reduced the credibility and validity of health information in mass media.

Books or pamphlets are professional sources of health information, though they may lack timeliness and efficiency. As for the help of relatives and friends, the quality of the health information thus obtained can't be assured.

\section{The internet}

'Interactive health communication', as was defined by Robinson et al. in 1998, refers to the interaction of an individual-consumer, patient, caregiver or professional-with or through an electronic device or communication technology to access or transmit health information or to receive guidance and support on a health-related issue' [12]. With the rapid development and spread of internet and mobile device, 'interactive health communication' has experienced a boost. Many developed countries have incorporated the Internet into their healthcare delivery system a decade ago [13]. In China, the number of internet users reached 6.68 billion in 2015, representing $48.8 \%$ of its population. Venture capital invested in medical field in internet added up to 6.9 billion dollars [14]. Embracing the appropriate policy environment, technology development, social environment and the involvement of giant companies, it's estimated that the medical field in the internet will expand 10 times in 10 years in China [15].

Patients access online health information primarily in three ways: searching directly for health web pages, participating in support groups and consulting with health professionals online [2]. Searches are mainly concerned with diagnoses, treatment information related to physical illnesses as well as performance reports regarding providers and hospitals [2,16]. These kinds of information may influence patients' choices of providers and doctors and their medical decision making [17]. Secondly, online groups provide social support, disseminate information, share experiences and behavioural models; and empower their participants, fulfilling the functions of a community [18-20]. Examples include Baidu Tieba forums and QQ groups (two of China's biggest social network platforms). Thirdly, previous surveys in US, 2000 suggested that about one in five physicians e-mail patients and 3.7 million patients e-mail their doctors [2]. The Chinese concept of 'internet plus medicine' was brought up in recent years, referring to the crossover development of internet and medicine. An advanced form of online medical service has been under experiment since Dec $7^{\text {th }}, 2015$ in Wuzhen, Zhejiang, China.

Nevertheless, there are obstacles facing the development of interactive health communication. The first and foremost problem that medical professionals and patients concern about is the quality of online health information [3,21]. The condition of online health information now in China is similar to that of USA in 1990s, when the 'incomplete, misleading and inaccurate' health information flooded $[3,22]$. Though the Code of Conduct for medical/health websites (HONcode) is established by the Health on the Net Foundation in 2004 [23], it's barely conducted in China. Uncontrolled and unmonitored publication with little peer review still permeates China's internet. In the second place, the problem of unequal access is significant. Those in the greatest need, especially the elderly, are least likely to have Internet access [24]. Report from China Internet Network Information Center (CNNIC) revealed that adults aged 60 or above constitute only $2.4 \%$ of all Internet users in 2015 [14]. Those in the greatest need often have low information access due to lower health literacy [25], which is defined as 'the degree to which individuals have the capacity to obtain, process, and understand basic health information and services needed to make appropriate health decisions' [26]. Last but not least, poor design features make the health information functionally inaccessible. The overload and disorder of internet information result in more difficulties in locating valid health information. In addition, the inconvenience of websites and the rapid update of information make information locating even harder [2]. 


\section{Conclusion and Future Perspective}

In conclusion, because of the insufficient health information doctors are able to provide, and the trust crisis between doctors and patients arising in recent years, patients rely more on alternative access to health information for complementing. Traditional alternative sources such as mass media, books or pamphlets, relatives and friends suffer low timeliness, credibility and efficiency. Though the current boom of online health information is promising, low quality of information, unequal access and poor design features have become obstacles.

Websites providing authentic health information search, supported by Chinese authority and professional institutions, should be established in the near future, like the NHS Choices in UK and the Health finder and Medline Plus in U.S. In such websites, high-quality, evidence-based information will be ensured by rigorous peer review, user- and professional-rating systems and high compliance with the HON code, information characteristics well designed to enhance the delivery of information without affecting the quality of message content [27]. In realization of this, logical organization based on user's perspective is required for convenience purpose. Links between websites to facilitate the locating of specific information should also be set [2]. Options for the hearing- and sight-impaired or the elder (e.g. visual and auditory images, font size and language [28]) should be provided [27].

Besides, doctors or basic healthcare providers in community and countryside will play an increasingly important role in promoting residents' health literacy. According to a case study, a4-week e-health program (1.5 hrs per week) was conducted to improve the elder's independent access to and use of health-related information in the form of physical exercise videography from a government-sponsored website [29]. In parallel with other study results, training programs not only enhance the effect with which the elder use the Internet to seek health information but also promote their psychological well-being, including lower anxiety toward computer use, higher sense of confidence, and higher self-efficacy [30]. A systematic review article [31] of interventions to improve health literacy, including 52 studies from different countries, gives us more information. According to the literature, five types of interventions were associated with changes in health literacy: group education, individual counseling, multiple interventions, web/computer, and telephone and written material. These interventions relate to each other in a complementary way, without any one of them being the most effective. Another finding is that the effectiveness of interventions has little to do with its intensity, suggesting that interventions could be adopted and supported on a larger scale within health systems due to the high benefit-cost ratio. Primary healthcare providers are relatively less burdened in China and hence are able to conduct such interventions in health literacy universally.

As for secondary and tertiary healthcare providers, they will provide more professional services in the future. For example, clinical pharmacy services, although still in the early stage of development, are becoming firmly established with the support of China's Ministry of Health $(\mathrm{MOH})$ [32]. The pharmacist counselling will be widely received by patients and proved to increase patients' understanding of medicines [33].

\section{Acknowledgements}

The authors express their gratitude to Yiran Guan for her assistance on revising the manuscript and the three anonymous reviewers for their valuable feedback. Further, the authors declare that there is no potential conflict of interest.

\section{References}

1. Tang S, Meng Q, Chen L, Bekedam H, Evans T, et al. (2008) Tackling the challenges to health equity in China. Lancet 372: 1493-1501.

2. Cline RJ, Haynes KM (2001) Consumer health information seeking on the Internet: the state of the art. Health Educ Res 16: 671-692.

3. Yan YY (2010) Online health information seeking behavior in Hong Kong: an exploratory study. J Med Syst 34: 147-153.

4. Corpman DW (2013) Mobile health in China: a review of research and programs in medical care, health education, and public health. J Health Commun 18: 1345-1367.

5. Siow TR, Soh IP, Sreedharan S, Das DS, Tan PP, et al. (2003) The Internet as a source of health information among Singaporeans: prevalence, patterns of health surfing and impact on health behaviour. Annals of the Academy of Medicine, Singapore 32: 807-813.

6. Hu Y, Zhang Z (2015) Patient education - A route to improved patient experience in Chinese hospitals? Patient Educ Couns.

7. CMDA (2015) White paper of Chinese doctors' practice: Chinese Medical Doctor Association.

8. Yezli S, Li H (2012) Antibiotic resistance amongst healthcare-associated pathogens in China. International Journal of Antimicrobial Agents 40: 389-397.

9. Wagstaff A (2007) Health systems in East Asia: what can developing countries learn from Japan and the Asian Tigers? Health Econ 16: $441-456$.

10. Li Y, Xu J, Wang F, Wang B, Liu L, et al. (2012) Overprescribing in China, driven by financial incentives, results in very high use of antibiotics, injections, and corticosteroids. Health Aff (Millwood) 31: 1075-1082.

11. Huang S, Ding X (2011) Violence against Chinese health-care workers, p: 1747.

12. Robinson TN, Patrick K, Eng TR, Gustafson D (1998) An evidence-based approach to interactive health communication: a challenge to medicine in the information age. Science Panel on Interactive Communication and Health. JAMA 280: 1264-1269.

13. Campbell RJ, Nolfi DA (2005) Teaching elderly adults to use the Internet to access health care information: before-after study. J Med Internet Res 7: e19.

14. CNNIC CIN (2015) Report of the $36^{\text {th }}$ China internet development statistics: China Internet Network.

15. ReMED IMC (2015) Report of the development of Chinese internet medicine. Internet Medicine China [reMED]: Communication University of China.

16. Boyer C, Selby M, Scherrer JR, Appel RD (1998) The Health On the Net Code of Conduct for medical and health Websites. Comput Biol Med 28: 603-610.

17. Wilkins AS (1999) Expanding Internet access for health care consumers. Health Care Manage Rev 24: 30-41.

18. Sharf BF (1997) Communicating breast cancer on-line: support and empowerment on the Internet. Women Health 26: 65-84.

19. King SA, Moreggi D (1998) Internet therapy and self-help groups-the pros and cons.

20. Nochi M (1998) Struggling with the labeled self: people with traumatic brain injuries in social settings. Qual Health Res 8: 665-681.

21. Maugans TA, McComb JG, Levy ML (1998) The internet as a pediatric neurosurgery information resource. Pediatr Neurosurg 28: 186-190.

22. Silberg WM, Lundberg GD, Musacchio RA (1997) Assessing, controlling, and assuring the quality of medical information on the Internet: Caveant lector et viewor--Let the reader and viewer beware. JAMA 277: 1244-1245.

23. Kasztelowicz P (2004) HON Code of Conduct (HONcode) for medical and health Web sites. 
Citation: Liu M, Hu Y (2016) A Mini Review of Patients'Access to Health Information in China. J Health Med Inform 7: 237. doi: 10.4172/2157-7420.1000237

Page 4 of 4

24. Eng TR, Maxfield A, Patrick K, Deering MJ, Ratzan SC, et al. (1998) Access to health information and support: a public highway or a private road? JAMA 280: 1371-1375.

25. Parker RM, Williams MV, Weiss BD, Baker DW, Davis TC, et al. (1999) Health literacy-Report of the Council on Scientific Affairs. Jama-Journal of the American Medical Association 281: 552-557.

26. Services UDOH (2000) Healthy People 2010. With Understanding and Improving Health and Objectives for Improving Health, US Government Printing Office 17, Washington: DC.

27. Ambre J, Guard R, Perveiler FM, Renner J, Rippen H (1997) White paper: Criteria for assessing the quality of health information on the internet Working Draft: Health Information Technology Institute of Mitretek System.

28. Johnson R, Kent S (2007) Designing universal access: web-applications for the elderly and disabled. Cognition, Technology \& Work 9: 209-218.

29. Tse MM, Choi KC, Leung RS (2008) E-health for older people: the use of technology in health promotion. Cyberpsychol Behav 11: 475-479.
30. Chu A, Huber J, Mastel-Smith B, Cesario S (2009) "Partnering with Seniors for Better Health": computer use and Internet health information retrieval among older adults in a low socioeconomic community. J Med Libr Assoc 97: 12-20.

31. Taggart J, Williams A, Dennis S, Newall A, Shortus T, et al. (2012) A systematic review of interventions in primary care to improve health literacy for chronic disease behavioral risk factors. BMC Fam Pract 13: 49.

32. Penm J, Moles R, Wang H, Li Y, Chaar B (2014) Factors affecting the implementation of clinical pharmacy services in China. Qual Health Res 24: 345-356.

33. O'Neil CK, Poirer TI (1998) Impact of patient Knowledge, patientpharmacist relationship, and drug perceptions on adverse drug therapy outcomes. Pharmacotherapy: The Journal of Human Pharmacology and Drug Therapy 18: 333-340. 